\title{
An alternative approach in hydrograph decomposition and separation of the baseflow
}

\author{
Víctor Manuel Salas Aguilar ${ }^{1 *}$, Víctor Reyes Gómez ${ }^{2}$, Fernando Paz Pellat ${ }^{1}$ \\ ${ }^{1}$ Posgrado en Hidrociencias, COLPOS, Carretera México-Texcoco Km. 36.5 Montecillo, Texcoco 56230, Estado de México, México. \\ ${ }^{2}$ Instituto Nacional de Ecología, Miguel de Cervantes 120, Complejo Industrial Chihuahua 31109, Chihuahua, México. \\ * Corresponding author. Tel.: (52) 015558045900 Ext. 1154. E-mail: vsalasaguilar@gmail.com
}

\begin{abstract}
The identification of the moment when direct flow ends and baseflow begins is one of the biggest challenges of hydrological cycle modeling. The objectives of this research were: to characterize the recession curves (RC) and to separate the components of the hydrograph in a compact model. The RC were extracted from time series in three subwatersheds in Mexico. An expo-linear model was adapted and fitted to the master recession curves to find the transition point of the hydrograph and separate the baseflow. The model discriminated the RC in two decreasing ratios: one linear associated to the direct flow, and one exponential linked to the baseflow. The transition point between these two flows was obtained analytically by equaling both ratios. The derivation of a model parameter allowed to find the maximum points in the hydrometric time series, which were the criterion to separate the baseflow. The application of this model is recommended in the analysis of $\mathrm{RC}$ with different magnitudes from the flexibility and attachment to the fundaments of exhaustion of a reservoir.
\end{abstract}

Keywords: Recession curve; Groundwater discharge; Expo-linear model; Reservoir.

\section{INTRODUCTION}

The hydrograph analysis generally involves the mix of both direct flow and baseflow. The components of the hydrograph can be separated through the analysis of the recession curves $(\mathrm{RC})$, based on physical principles that govern the exhaustion of a reservoir (Kovács and Perrochet, 2008). The RC are described in two stages: the first is influenced by the direct flow (where there is a predominance of infiltration to the saturated zone), and the second is called baseflow, which happens when the saturated zone tends to discharge (Dewandel et al., 2003).

The quantitative analysis of the RC has been studied with two mathematical formulations; the Maillet formula, derived from an exponential function that implies a linear relationship between the degree of watershed saturation and its discharge (Maillet, 1905); and the Boussinesq equation (1904), which refers that the discharge of a watershed adjusts to a non-linear tendency. These equations do not allow the complete characterization of the RC (Mangin, 1970). Because of this, several authors have proposed more complex models that consider the effects of several regimes (components) within the RC (Drogue, 1972; Malik, 2015; Vasileva and Komatina, 1997; Wang and Cai, 2010).

There are other techniques, like those proposed by Boughton (1986), Nejadhashemi et al. (2004), and He et al. (2016), where they identified the beginning of the baseflow through an empirical formula and call it the inflection point. In a negative tendency (exponential type) common in RC, there is no inflection point that can be analytically identified, so this expression is incorrectly used in the analysis.

The use of master recession curves (MRC) is a practical approach to avoid obstacles when extracting RC (Tallaksen, 1995). The MRC allow to join segments from recessions when there are series with limited time, incomplete, or there are too many recessions in a given period (Gregor and Malik, 2012). The importance of this approach is that it matches the central idea of hydrological works at the sub-watershed scale and al- lows to reproduce the hydrological functioning with the available information (Blume et al., 2007).

The analysis of RC requires a function that adapts to the linear tendency of the direct flow days after maximum runoff and follows the exponential pattern of the runoff once the baseflow has begun. Therefore, the objective of this work was to present a simple model that characterizes the components of the hydrograph in a single equation and to describe a robust technique that separates the flow regimes in time series.

\section{MATERIALS AND METHODS}

The Goudriaan and Monteith (1990) expo-linear model was adapted for hydrological purposes. The expo-linear model allowed to characterize the RC as two change ratios, the maximum runoff ratio $(C)$ which discriminated the phase associated with the direct flow (linear), and a relative runoff ratio $(k)$ associated to the baseflow (exponential). The solution to the model is given by:

$$
\begin{array}{ll}
\frac{d Q}{d t}=-C & Q(t)=-C\left(t+T_{b}\right) \\
\frac{d Q}{d t}=-k Q & Q(t)=Q(0) \exp ^{(-k t)}
\end{array}
$$

where $T_{b}$ is the base time that occurs when the runoff $Q(t)=0$, in the linear stage. To know the point of transition $\left(T_{t}\right)$ of the $\mathrm{RC}$, the runoff ratios must be equal. The expo-linear model is the solution of two types of flow represented by the differential equations (1) and (2), subject to the conditions given by the equality $k Q=C$. The adapted formula of the expo-linear model was:

$$
Q(t)=-\left(\frac{C}{k}\right) \ln \left(1+\exp \left[-k\left(t-T_{b}\right)\right]\right)
$$


The transition point was calculated as follows:

$T t F s=T_{b}+(0.541 /-k)$

where $T t F s$ is the time when the baseflow begins (maximum discharge).

The recharge-discharge relation was balanced at the $Q(0)$ point, the discharge begins at this point and reaches a maximum value at $T t F s$, from here, all the tendency of the recession is underground discharge.

The hydrograph components were separated under the assumption that discharge is the result of the superposition of laminar flows (baseflow) expressed by one exponential function and a turbulent flow (direct flow) pointed out by a linear function (Figure 1a). The estimation of the $T_{b}$ parameter allowed to know the transition period in time series, which happened between the maximum runoff and the laminar flow. To do so, the expo-linear equation of $T_{b}$ is:

$T_{b}=-\frac{\left(-k * t+\ln \left(\exp \left(Q * \frac{k}{C}\right)-1\right)\right)}{k}$

The equation (5) was solved and derived based on $Q$ :

$$
\frac{d T b}{d Q}=\frac{-\exp ^{(Q k / C)}}{C\left(\exp ^{(Q k / C)}-1\right)}
$$

The derivate was added to the equation that calculates the transition point:

$T t F b=\frac{d T b}{d Q}+(0.541 /-k)$
The adjustment of the parameters of the expo-linear model and the formulation of the derivate of $T_{b}$ allowed to estimate the maximum point of $T t F b$, by substituting $Q$ for the hydrometric registries of the time series (Figure 1b). The obtained points were interpolated through a linear function of the scipy.interpolate library within the Python ${ }^{\mathrm{RM}}$ programming language (Python Software Fundation) to separate baseflow.

A concept test was done in three sub-watersheds with similar physiographical conditions in central Mexico (Table 1). The hydrometric registries of the three sub-watersheds were obtained from the National Bank of Surface Waters (Banco Nacional de Aguas Superficiales - BANDAS, 2011). The period of the data varied from 2000 to 2009. The Recesión Curve RC 4.0 software was used (Gregor and Malik, 2012) to extract the RC. A minimum of ten days of descending registries was established to consider the RC. The MRC were built to adjust the parameters of the expo-linear model (Gregor and Malik, 2012). The adjustment criterion was the root mean square error (RMSE).

\section{RESULTS}

Figure 2 shows the adjustment of the expo-linear model parameters for each sub-watershed. The transition time was related with the number of days that elapses for the direct flow to be negligible and for the baseflow to begin. The direct flow is quickly discharged in sub-watershed 26178 (Figure 2a), as it showed the lowest point of transition (TtFs $=3.2$ days), followed by sub-watersheds 26354 (TtFs $=7.6$ days) and 26056 $(T t F s=8.8$ days) (Figure $2 \mathrm{c}$ and $2 \mathrm{~b})$. The variability of the model was also lowest in the sub-watershed 26178 (RMSE = 7.70). This suggests that it did not present perturbations that affect the form of the RC. We observed that the calculation of the transition point is an indicator of the perturbation in the discharge level of each sub-watershed, so this hypothesis will be evaluated in later research.

Table 1. Physiographic variables of the study sub-watersheds.

\begin{tabular}{lccccccccccl}
\hline$*$ ID & $\begin{array}{c}\text { Longitude } \\
\left({ }^{\circ}\right)\end{array}$ & $\begin{array}{c}\text { Latitude } \\
\left({ }^{\circ}\right)\end{array}$ & $\begin{array}{c}\text { Area } \\
\left(\mathrm{km}^{2}\right)\end{array}$ & $\begin{array}{c}* P m a \\
(\mathrm{~mm})\end{array}$ & $\begin{array}{c}* H g v \\
(\mathrm{~mm})\end{array}$ & $\begin{array}{c}\text { Hmin } \\
*(\mathrm{~m})\end{array}$ & $\begin{array}{c}* \text { Hmax } \\
(\mathrm{m})\end{array}$ & $\begin{array}{c}\text { *Hmed } \\
(\mathrm{m})\end{array}$ & $\begin{array}{c}* R \\
(\mathrm{~m})\end{array}$ & $\begin{array}{c}* S \\
(\%)\end{array}$ & Rock type \\
\hline 26178 & -99.81 & 19.53 & 49 & 841 & 1545 & 2234 & 3361 & 2477 & 243 & 6 & Basalt rock and andesites \\
26056 & -99.07 & 19.57 & 3711 & 732 & 1538 & 2207 & 5203 & 2435 & 228 & 5 & $\begin{array}{l}\text { Gravel, sand, and lime: alluvial and } \\
\text { lacustrine deposits }\end{array}$ \\
26354 & -99.32 & 19.68 & 207 & 811 & 1539 & 2245 & 3431 & 2462 & 217 & 8 & Basalt rock and andesites \\
\hline
\end{tabular}

*ID: Identification of the sub-watershed, Pma: mean annual rainfall, Hgv: mean annual evapotranspiration, Hmin: minimum altitude, Hmax: maximum altitude, Hmed: mean altitude, $R$ : altitude range, $S$ : slope
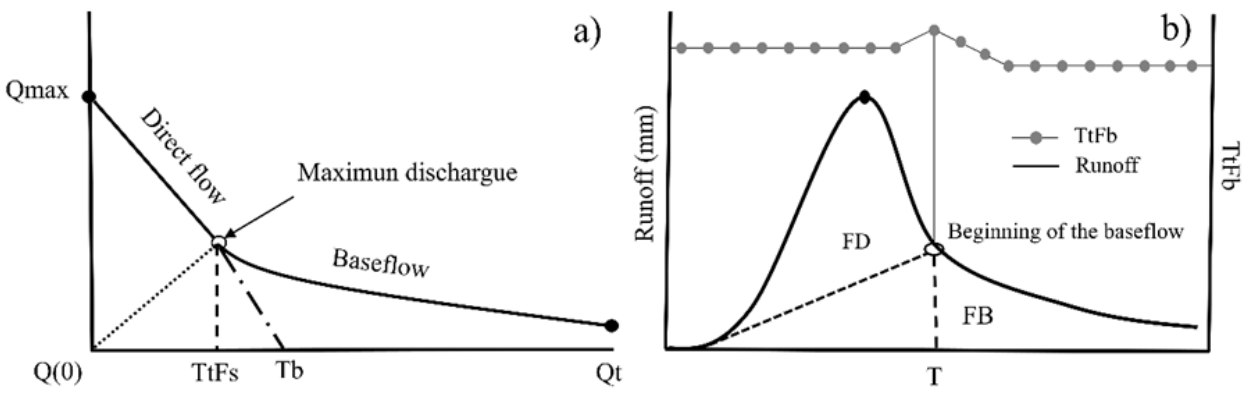

Fig. 1. Components that determine a hydrograph. Flow stages determined by the expo-linear model (a). Maximum point calculated with the derivation of $T b(T t F b)$ that corresponds to the beginning of the baseflow in time series. 

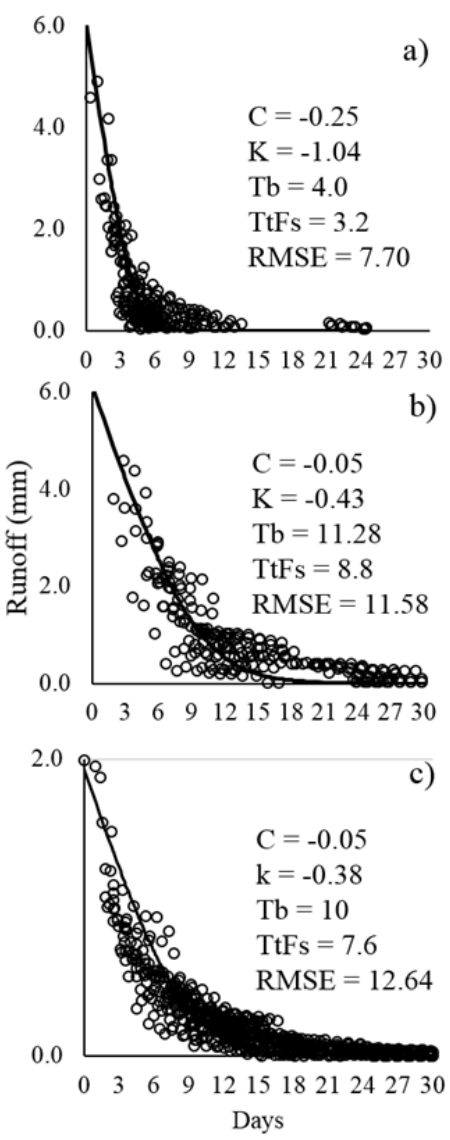

Fig. 2. Estimation of the time of transition between the direct flow and the baseflow, and adjustment of the parameters of the expolinear model.

The separation of the baseflow respect to the direct flow of the three sub-watersheds is shown in Figure 3. Sub-watershed 26053 (Figure 3c) lies in a discharge zone, unlike subwatersheds 26178 (Figure 3a) and 26354 (Figure 3b), which are located in recharge zones (Peñuela and Carrillo, 2013), which accounts for its greater direct flows.

The maximum $T t F b$ points did not show in the high values of the hydrograph. When $Q$ begins to be constant (after the baseflow begins), the derivate of $T_{b}$ nears zero. Because of this, days after the maximum runoffs, the $T t F b$ values were more frequent. This is important since, generally, the equations to estimate baseflow are imitations of the hydrograph registries; this is to say, they describe in low signals any movement registered in the time series. This makes no sense from a hydrological point of view, as underground water reaches a saturation point and is not logical for baseflow to keep the same tendency of direct flow when it shows maximum peaks.

\section{DISCUSSION}

The methods to separate baseflow from direct flow, such as graphic methods (Linsley et al., 1982; Sujono et al., 2004), digital filters (Chapman and Maxwell 1996; Wittemberg and Sivapalan, 1999), and analytical solutions of recession curves (Brutsaert and Nieber, 1977; Szilagyi and Parlange, 1998) have the difficulty of identifying the point in time when surface runoff stops and underground discharge begins. This transition point is often chosen ambiguously by diverse researchers (Tallaksen, 1995).
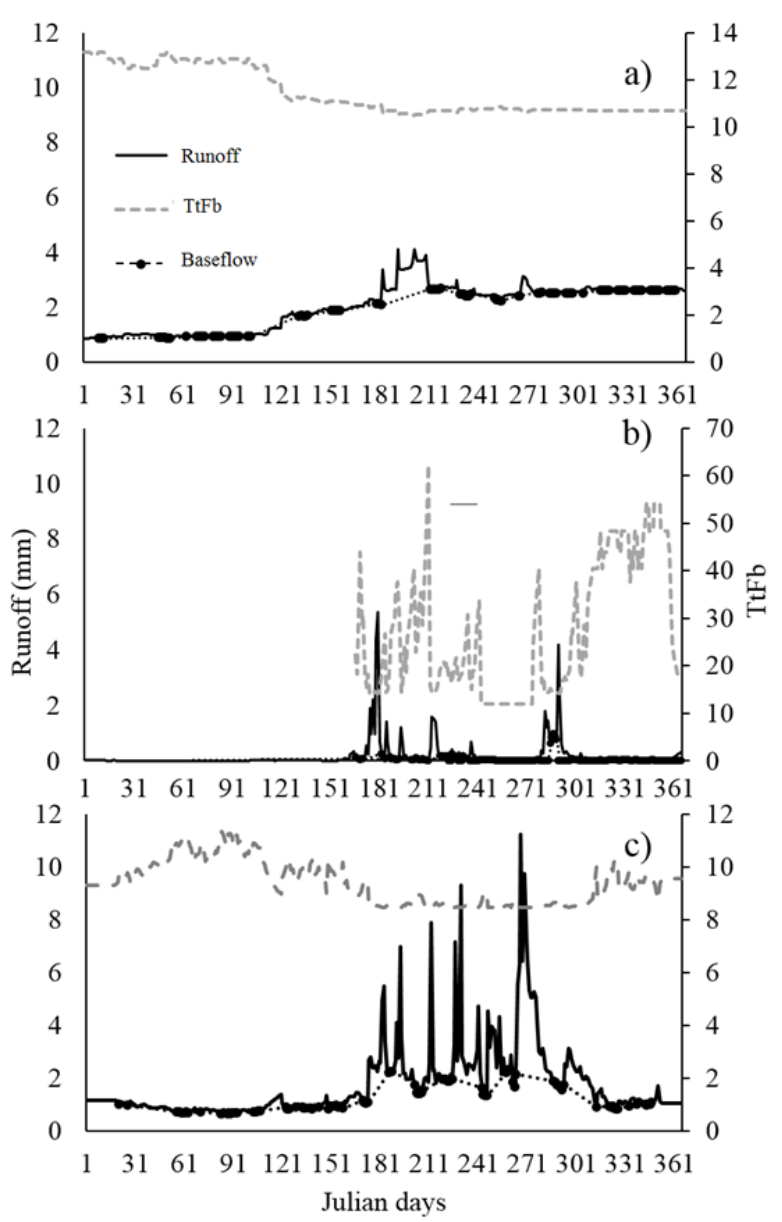

Fig. 3. Separation of the baseflow, with reference to the derivation of the expo-linear model.

The prevailing justification is the difficulty to find a simple equation that completely describes the hydrograph recession. That is why several regimes are considered in the discharge process. Padilla et al. (1994) suggested that the discharge in karstic systems is represented by two components: one linear, described by the Maillet formula associated with the recession of the saturated zone; and the other, non-linear, referred by a homographic formula related to the non-saturated zone. Malik (2015) implemented an iterative solution of several exponential and linear relationships for the hydrograph separation.

Blume et al. (2007) developed a method to find the transition point, called " $\mathrm{k}$ constant". Their model describes the transition point and allows to estimate the baseflow, as we do. However, it does not completely and parametrically discriminate the RC; this is to say, there is no parameter associated to the direct flow component.

The present proposal allows to completely simulate the RC so it was possible to analytically find the transition time between direct flow and baseflow with a single equation. The adaptation of the expo-linear model to describe the recession curve is based on the fact that once the maximum effect in a storm is reached, there is a period when the riverbed mostly receives turbulent flow which ceases once the linear stage of the model reaches the transition point. This makes the proposed model attractive to separate the components of the hydrograph, with a hydrological basis, unlike other formulations that require experience from the modeler, or are set by fixing the equation (Nejadhashemi et al., 2004). 


\section{CONCLUSIONS}

The proposed method allowed to find the starting point of baseflow with a compact model that discriminates the recession curves in two components, one linear, linked to the direct flow, and the other exponential, attributed to the baseflow.

The maximum points of this derivation were the criterion for the separation of three sub-watersheds baseflow in time series.

One advantage of the expo-linear model is its flexibility to the recession curves dynamics, independently of their magnitude. The model simulated the recession curves in different subwatersheds, so it was adapted adequately to the hydrological principles of the reservoir exhaustion.

\section{REFERENCES}

Banco Nacional de Datos de Aguas Superficiales (BANDAS), 2011. Consulta de Datos Hidrométricos, de Presas y Sedimentos. Comisión Nacional del Agua: México. Available online:

www.conagua.gob.mx/CONAGUA07/contenido/documento s/portada\%20bandas.htm (accessed on 25 January 2016).

Blume, T., Zehe, E., Bronstert, A., 2007. Rainfall-runoff response, event-based runoff coefficients and hydrograph separation. Hydrological Sciences Journal, 52, 843-862.

Boughton, W.C., 1986. Linear and curvilinear baseflow recessions. Journal of Hydrology (NZ), 25, 41-48.

Boussinesq, J., 1904. Recherches théoriques sur l'écoulement des nappes d'eau infiltrées dans le sol et sur le débit de sources. J. Math. Pure Appl., 10, 5-78.

Brutsaert, W., Nieber, J.L., 1977. Regionalized drought flow hydrographs from a mature glaciated plateau. Water Resour. Res., 133, 637-643.

Chapman, T.G., Maxwell, A., 1996. Baseflow Separation Comparison of Numerical Methods with Tracer Experiments. In. Proc. 23rd Hydrology and Water Resources Symposium, Hobart Australia, pp. 539-545.

Dewandel, B., Lachassagne, P., Bakalowicz, M., Weng, P.H., Al-Malki, A., 2003. Evaluation of aquifer thickness by analysing recession hydrographs. Application to the Oman ophiolite hard-rock aquifer. Journal of Hydrology, 274, 248269.

Drogue, C., 1972. Analyse statistique des hydrographes de decrues des sources karstiques. Journal of Hydrology, 15, 49-68.

Goudriaan, J., Monteith, J.L., 1990. A mathematical function for crop growth based on light interception and leaf area expansion. Annals of Botany, 66, 695-701.

Gregor, M., Malík, P., 2012. Construction of master recession curve using genetic algorithms. Journal of Hydrology and Hydromechanics, 60, 3-15.
He, S., Li, S., Xie, R., Lu, J., 2016. Baseflow separation based on a meteorology-corrected nonlinear reservoir algorithm in a typical rainy agricultural watershed. Journal of Hydrology, 535, 418-428.

Kovács, A., Perrochet, P., 2008. A quantitative approach to spring hydrograph decomposition. Journal of Hydrology, $352,16-29$.

Linsley, R.K., Kohler, M.A., Paulhus, J.L.H., 1982. Hydrology for Engineers. McGraw-Hill, NewYork, 508 p.

Maillet, E., 1905. Essais d'hydraulique souterraine et fluviale. Librairie Sci., A. Hermann, Paris, 218 p.

Malik, P., 2015. Evaluating discharge regimes of karst aquifer In: Karst Aquifer - Characterization and Engineering. Springer International Publishing. Switzerland, pp. 205-239.

Mangin, A., 1970. Contribution à l'étude d'aquifères karstiques à partir de l'analyse des courbes de décrue et de tarissement. Ann. Speleol., 25, 581-610.

Nejadhashemi, A.P., Shirmohammadi, A., Sheridan, J.M., Montas, H.J., 2004. Evaluation of analytical methods for streamflow partitioning. In: Proc. ASAE Annual International Meeting 2004, Canada, pp. 2357-2377.

Padilla, A., Pulido, A., Mangin, A., 1994.Relative importance of baseflow and quickflow from hydrographs of karst spring. GroundWater, 32, 267-277.

Peñuela, L., Carrillo, J., 2013. Definición de zonas de recarga y descarga de agua subterránea a partir de indicadores superficiales: centro-sur de la Mesa Central, México. Investigaciones Geográficas. Boletín del Instituto de Geografía, 2013, 18-32.

Sujono, J., Shikasho, S., Hiramatsu, K., 2004. A comparison of techniques for hydrograph recession analysis. Hydrological Processes, 18, 403-413.

Szilagyi, J., Parlange, M.B., 1998.Baseflow separation based on analytical solutions of the Boussinesq equation. Journal of Hydrology, 204, 251-260.

Tallaksen, L.M., 1995. A review of baseflow recession analysis. J. Hydrol., 165, 349-370

Vasileva, D., Komatina, M., 1997. A contribution of the alpha recession coefficient investigation in karts terrains. Theor. Appl. Karstol., 10, 45-54.

Wang, D., Cai, X., 2010. Recession slope curve analysis under human interferences. Advances in Water Resources, 33, 1053-1061.

Wittenberg, H., Sivapalan, M., 1999. Watershed groundwater balance estimation using streamflow recession analysis and baseflow separation. Journal of Hydrology, 219, 20-33.

Received 26 January 2017 Accepted 1 June 2017 